Keywords: pancreatic cancer; pancreatic intraepithelial neoplasia (PanIN); chemokines and chemokine receptors; tumour differentiation

\title{
Early expression of the fractalkine receptor CX3CR1 in pancreatic carcinogenesis
}

\author{
G Celesti ${ }^{1,11}$, G Di Caro ${ }^{1,2,11}$, P Bianchi ${ }^{1}$, F Grizzi $^{1}$, F Marchesi ${ }^{3}$, G Basso ${ }^{1,4}$, D Rahal ${ }^{5}$, G Delconte ${ }^{1}$,
}

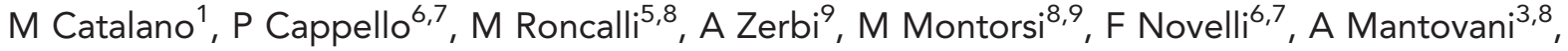
P Allavena ${ }^{3}$, A Malesci ${ }^{\star}, 8,10$ and L Laghi ${ }^{\star}, 1,10$

${ }^{1}$ Laboratory of Molecular Gastroenterology, Department of Gastroenterology, Humanitas Clinical and Research Center, Via Manzoni, 56, 20089 Rozzano, Milan, Italy; ${ }^{2}$ PhD Programs in Pathology and Neuropathology, University of Milan, Via Manzoni, 56, 20089 Rozzano, Milan, Italy; ${ }^{3}$ Department of Immunology and Inflammation, Humanitas Clinical and Research Center, Via Manzoni, 56, 20089 Rozzano, Milan, Italy; ${ }^{4}$ School of Molecular Medicine, University of Milan, Via Manzoni, 56, 20089 Rozzano, Milan, Italy; ${ }^{5}$ Department of Surgical Pathology, Humanitas Clinical and Research Center, University of Milan, Via Manzoni, 56, 20089 Rozzano, Milan, Italy; ${ }^{6}$ Centro Ricerche Medicina Sperimentale, Azienda Universitaria Ospedaliera San Giovanni Battista, University of Torino, Via Cherasco, 15, 10126 Torino, Italy; ${ }^{7}$ Department of Medicine and Experimental Oncology, University of Torino, Via Cherasco, 15, 10126 Torino, Italy; ${ }^{8}$ Department of Medical Biotechnologies and Translational Medicine, University of Milan, Milan, Italy; ${ }^{9}$ Department of General Surgery, Humanitas Clinical and Research Center, University of Milan, Via Manzoni, 56, 20089 Rozzano, Milan, Italy and ${ }^{10}$ Department of Gastroenterology, Humanitas Clinical and Research Center, Via Manzoni, 56, 20089 Rozzano, Milan, Italy

Background: In pancreatic ductal adenocarcinoma (PDAC), fractalkine receptor CX3CR1 contributes to perineural invasion (PNI). We investigated whether CX3CR1 expression occurs early in PDAC and correlates with tumour features other than PNI.

Methods: We studied CX3CR1 and CX3CL1 expression by immunohistochemistry in 104 human PDAC and coexisting Pancreatic Intraepithelial Neoplasia (PanIN), and in PdxCre/LSL-Kras ${ }^{G 12 D}$ mouse model of PDAC. CX3CR1 expression in vitro was studied by a spheroid model, and in vivo by syngenic mouse graft of tumour cells.

Results: In total, 56 (53.9\%) PDAC expressed CX3CR1, 70 (67.3\%) CX3CL1, and 45 (43.3\%) both. CX3CR1 expression was independently associated with tumour glandular differentiation $(P=0.005)$ and $P N I(P=0.01)$. Pancreatic Intraepithelial Neoplasias were more frequently CX3CR1 $+(80.3 \%, P<0.001)$ and CX3CL1 + $(86.8 \%, P=0.002)$ than matched cancers. The survival of PDAC patients was better in those with CX3CR1 + tumour $(P=0.05)$. Mouse PanINs were also CX3CR1 ${ }^{+}$and $-\mathrm{CL} 1^{+}$. In vitro, cytokines significantly increased CX3CL1 but not CX3CR1 expression. Differently, CX3CR1 was upregulated in tumour spheroids, and in vivo only in well-differentiated tumours.

Conclusion: Tumour differentiation, rather than inflammatory signalling, modulates CX3CR1 expression in PanINs and PDAC. CX3CR1 expression pattern suggests its early involvement in PDAC progression, outlining a potential target for interfering with the PanIN transition to invasive cancer.

Pancreatic cancer, namely ductal adenocarcinoma (PDAC), is a major health problem, the death rate approaching the incidence of the disease (Hidalgo, 2010). The majority of PDACs are diagnosed at an advanced stage, beyond any possibility of cure. A better understanding of the early neoplastic changes in the pancreas might help anticipating the diagnosis and counteracting the rapid

\footnotetext{
*Correspondence: Dr A Malesci; E-mail: alberto.malesci@humanitas.it or Dr L Laghi; E-mail: luigi.laghi@humanitas.it

${ }^{11}$ These authors contributed equally to this work.
}

Revised 9 July 2013; accepted 22 August 2013; published online 1 October 2013

(C) 2013 Cancer Research UK. All rights reserved 0007-0920/13 
progression of pancreatic cancer. Microscopic pre-cancerous lesions (Pancreatic Intraepithelial Neoplasia, PanIN) house KRAS mutations (Jones et al, 2008; Sipos et al, 2009) and accumulate further gene damage along progression to cancer (Jones et al, 2008). However, gene damage is not the only driver of pancreatic carcinogenesis, PDAC being characterised by a dense stromal reaction, referred to as desmoplasia (Farrow et al, 2008), which is an active partner in disease progression (Hwang et al, 2008; Vonlaufen et al, 2008). Stromal cells produce cytokines and growth factors that establish an active tumour-stroma cross-talk (Farrow et al, 2008; Hwang et al, 2008; Vonlaufen et al, 2008). Mediators of the cross-talk between cancer and microenvironment include chemokines, small chemotactic cytokines, and their receptors (Mantovani et al, 2008; Wang et al, 2008; Balkwill, 2012). Tumour expression of chemotactic molecules modifies the behaviour of cancer cells and tumour progression. The gain of expression of chemokine receptors enhances cancer invasion and spread by mediating cancer cell trafficking and metastasis homing (Mantovani et al, 2010). Chemokine expression in cancer may also affect immune recognition by the host, and may promote autocrine loops favouring the survival of tumour cells (Wang et al, 2008; Balkwill, 2012). The expression of the chemokine receptor CXCR4 has been associated with an enhanced progression of PDAC, and with stemness of cells with metastatic potential (Marchesi et al, 2004; Hermann et al, 2007). Surprisingly, the expression of CXCR4 and of its ligand CXCL12 begins in the preinvasive stages of pancreatic neoplasia (Thomas et al, 2008). The relevance of chemokine receptors in PDAC spread has been recently strengthened by the finding that tumour cells also express the chemokine receptor CX3CR1 (Marchesi et al, 2008). CX3CR1 forms a high-affinity axis (CX3-CR1-CL1) with its unique ligand CX3CL1 (also referred to as Fractalkine/Neurotactin), a mucinchemokine hybrid expressed by endothelial cells and neurons, either as a membrane-anchored adhesion molecule or as a secreted chemoattractant (Bazan et al, 1997; Pan et al, 1997). CX3CR1 expression was associated with the degree of perineural invasion (PNI), and PDAC cells expressing CX3CR1 were found to disrupt peripheral nerves once xenografted in mice (Marchesi et al, 2008). It is unknown whether the expression of the receptor occurs already in pre-invasive stages of pancreatic carcinogenesis, or alternatively, only in invasive cancer. Furthermore, limited information is available as to the expression of the ligand in PDAC (Xu et al, 2012), and as to whether tumour features and microenvironment cross-talk may affect CX3-CR1-CL1 status.

This study was aimed to investigate whether pancreatic cancer expresses CX3-CR1-CL1, already gaining the expression of these chemotactic molecules in pre-invasive stages, and whether an association exists with PDAC features and outcome. To these aims, we assessed the expression of CX3-CR1-CL1 in human PanINs and invasive cancers, as well as in PanINs of a Kras-mutated mouse model of pancreatic cancer, and tested their responsiveness to cytokines and their expression in tumours propagated in vivo.

\section{MATERIALS AND METHODS}

Patients and tissues specimens. We retrospectively retrieved the tissue specimens from 104 patients who underwent resective surgery for pancreatic cancer at the Humanitas Clinical and Research Center, Rozzano, Milan, Italy. Seventy-six PDAC also harboured precursor lesions.

For each patient included in the study, demographics and complete pathological data at diagnosis were available. Specimens were reviewed by pathologists unaware of molecular data. Tumour pathological staging, histopathological typing, tumour grade, and the presence or absence of PNI and/or of extramural vein invasion were assessed in each PDAC. The absence of nodal involvement was considered as appropriate only for PDAC in which $\geqslant 12$ lymph nodes had been assessed. The study was conducted in accordance with the guidelines of the Ethics Committee of the Hospital, and the referring physician obtained the informed consent of the patients to the treatment of their personal data at the time of surgery. The overall survival (OS) was calculated from diagnosis until death, and deceases were documented by obtaining the death certificate in every case.

Mouse models of pancreatic cancer. Female and male mice carrying mutated KrasG12D or Trp53R172H (C57BL/6;129SvJae $\mathrm{H}-2 \mathrm{~b} ; \mathrm{d}$ ) under the endogeneous promoter and flanked by LoxSTOP-Lox cassettes were bred by us (Hingorani et al, 2005). PdxCre/LSL-Kras ${ }^{G 12 D}$ and PdxCre/LSL-Kras ${ }^{G 12 D}-T_{r p} 53^{R 172 H}$ double mutant mice, developing PDAC, were generated by crossing them with $\mathrm{C} 57 \mathrm{BL} / 6$ mice, expressing Cre recombinase, under a specific pancreatic transcriptional factor Pdx-1 (pancreatic duodenum homeobox 1) promoter. Mice were screened by PCR using tail DNA amplified by specific primers to Lox-P cassette flanking K-ras gene and Cre recombinase gene. Mice were kept under pathogenfree conditions at the Molecular Biology Center, University of Turin, and treated in accordance with European Union and University of Turin Guidelines. Pancreata from wild-type or PdxCre/LSL-Kras ${ }^{G 12 D}$ mutant mice killed at 1, 6, and 9 months from birth were subsequently fixed in formalin and embedded in paraffin.

Immunohistochemistry. Two- $\mu$ m-thick sections were processed for immunohistochemistry (IHC). After deparaffining and rehydration, the sections were immersed in antigen retrieval bath, incubated with $3 \% \mathrm{H}_{2} \mathrm{O}_{2}$ for $15 \mathrm{~min}$, and treated for $2 \mathrm{~h}$ at room temperature with primary antibodies raised against CX3CR1 (Ab8021, polyclonal rabbit anti-human; Abcam, Cambridge, UK) and CX3CL1 (AF365, polyclonal goat anti-human; R\&D Systems, Minneapolis, $\mathrm{MN}$, USA), or with rabbit or goat IgG (Dako, Milan, Italy) to serve as negative controls, followed by 30-min incubation with the DAKO Envision system (Dako) or the Anti-Goat Polymer kit (Biocare, San Francisco, CA, USA). Three-3'-diaminobenzidine tetrahydrochloride (Dako) was used as a chromogen and nuclei were lightly counterstained with haematoxylin (Medite, Bergamo, Italy).

Following IHC, in a subset of 15 PDAC harbouring CX3CR1 ${ }^{+}$ precursor lesions, PanINs were graded (54 PanIN-1, 43 PanIN-2, and 35 PanIN-3) and systematically evaluated for CX3CR1, CX3CL1, P16, and E-Cadherin expression according to the degree of dysplasia. P16/ CDKN2A and E-Cadherin IHC was performed with mouse monoclonal antibodies (Ab-7, 16P07; NeoMarkers Lab Vision, Fremont, CA, USA and clone NCH38; Dako, respectively).

In pancreata obtained from five PdxCre/LSL-Kras ${ }^{\text {G12D }}$ mutant mice, CX3CR1 IHC was performed with the same antibody used for human tissues, CX3CL1 expression was investigated by a polyclonal rabbit anti-mouse antibody (Torrey Pines Biolabs, East Orange, NJ, USA), and recognition of $\mathrm{S}-100^{+}$neural structures was achieved by monoclonal rabbit anti-mouse antibodies (Dako).

The intensity of CX3CR1 and CX3CL1 immunoreactivity was independently evaluated by two researchers (FG and CG). Immunoreactivity of infiltrating leukocytes and of endothelial cells served as positive internal controls for CX3CR1 and for CX3CL1, respectively. The semiquantitative evaluation of immunoreactivity of neoplastic ductal cells was first attributed through a 0-to-3 score: 0 (absence of immunoreactivity), 1 (weak), 2 (moderate), and 3 (strong), according to the level of immunoreactivity of most $(\geqslant 70 \%)$ neoplastic cells (Marchesi et al, 2008). Samples with 0-1 and with 2-3 immunoreactivity were subsequently pooled together, in a binary classification.

CX3CR1 and CX3CL1 mRNA expression in human and mouse ductal cell lines. Quantitative RT-PCR was employed to assess 
the expression of CX3CR1 and CX3CL1. Briefly, $1 \mu \mathrm{l}$ of sample cDNA was added to the PCR mixture containing $2 X$ Power SYBR Green Master Mix (Applied Biosystem, Life Technologies, Grand Island, NY, USA) and specific primers (for CX3CR1, 5'-GGGACT GTGTTCCTGTCCAT- $3^{\prime}$ and CX3CR1 5'-GACACTCTTGGG CTTCTTGC-3'; for CX3CL1 5'-TGGCTGCTCCGCTTGGC-3', and CX3CL1, $5^{\prime}$-CCTGGTTCTGTTGATAGTGGATGAG-3'); 18s RNA was used as a housekeeping gene. Data analysis was performed by comparative Delta Ct $(\Delta \Delta \mathrm{Ct})$ method, and fold change calculated using $2^{-\Delta \Delta \mathrm{Ct}}$.

Primary mouse pancreatic cell lines DT6606 (obtained from a tumour arisen in a PdxCre/LSL-Kras ${ }^{G 12 D}$ mouse) and K8484 (obtained from a tumour arisen in a PdxCre/LSL-Kras ${ }^{\text {G12D }}$ $\operatorname{Trp} 53^{R 172 H}$ mouse (Olive et al, 2009)) and human pancreatic cancer cell line A8184, MiaPacaII and AspCI were maintained in RPMI with $10 \%$ fetal bovine serum (FBS), $100 \mathrm{mg} \mathrm{ml}^{-1}$ of penicillin G, $50 \mathrm{mg} \mathrm{ml}^{-1}$ of Streptomycin and Ultraglutamine $2 \mathrm{~mm}$ and growth at $37^{\circ} \mathrm{C}, 5 \% \mathrm{CO}_{2}$ incubator. Cells seeded at $10^{6}$ cells per $\mathrm{ml}$ in six-well plates were stimulated with: interleukin1 beta (IL-1 $\beta)\left(20 \mathrm{ng} \mathrm{ml}^{-1}\right)$, tumour necrosis factor- $\alpha$ (TNF- $\alpha$ ) $\left(20 \mathrm{ng} \mathrm{ml}^{-1}\right)$ and interferon- $\gamma$ (IFN- $\gamma$ ) (500 units per $\mathrm{ml}$ ), interleukin-6 (IL-6), and transforming growth factor- $\beta$ (TGF- $\beta$ ) $\left(10 \mathrm{ng} \mathrm{ml}^{-1}\right)$ (Peprotech, Rocky Hill, NJ, USA) for $8 \mathrm{~h}$. Expression of CX3CR1 and CX3CL1 was assessed by qRT-PCR, as previously described by using primers for murine CX3CR1 $5^{\prime}$-ATTCTTCAT CACCGTCATCAG-3' ${ }^{\prime}, 5^{\prime}$-ACTAATGGTGACACCGTGCT-3' and for murine CX3CL1 $5^{\prime}$-GCTATCAGCTAAACCAGGAGTC-3', 5'-AGAAGCGTCTGTGCTGTGTC-3'.

Three-dimensional cell culture, immunofluorescence, and cell transplantation in syngenic mice. DT6606, K8484, A8184, and AspCI cells were mixed with Cultrex $\left(5 \times 10^{4}\right.$ cells per $\left.250 \mathrm{ml}\right)$ and plated in a 24-well plate. Cells were fixed overnight in 4\% PFA, washed twice with PBS $-/$ - plus $0.2 \%$ Tween. Immunofluorescence was performed after blockade of endogeneous non-specific antigens and permeabilisation by PBS - / - plus $10 \%$ normal goat serum, and $0.03 \%$ Triton. Cells were treated with primary antibodies raised against CX3CR1 (Ab8021; Abcam) overnight at $4{ }^{\circ} \mathrm{C}$, washed, and incubated with secondary antibody $1: 2000$ Alexa-fluor-488 (Invitrogen) for $1 \mathrm{~h}$ at room temperature. Subsequently, cells were incubated with 1:50 dilution of Alexa-fluor-594 phalloidin (Invitrogen). Nuclei were counterstained with DAPI (Invitrogen) 1:10.000. Imaging was obtained by confocal microscopy (Olympus, Tokyo, Japan). For RT-PCR analysis, mRNA from spheroid in culture was extracted by Trizol (Applied Biosystem), according to the manufacturer instruction, RT and analysis were performed as above described.

DT6606, K8484, and PANC02 cells were transplanted in syngenic C57BL/6 mice. We took advantage of a porous collagen biocompatible matrix, which provide a three-dimensional spatial architecture scaffold for the cells (Collagen Sponge CS-35; KOKEN Co Ltd, Tokyo, Japan). Collagen Sponges were loaded with DT6606, K8484, and PANC02 cells $\left(10^{6}\right.$ per ml) and intradermally injected in 15,8 , and $5 \mathrm{C} 57 \mathrm{BL} / 6$ mice, respectively, by a small incision on the left flank. Mice were killed after 2 weeks and tumours were immediately resected and fixed in formalin.

Statistical analysis. Categorical associations between expression of CX3CR1 and CX3CL1 and clinical-pathological factors of PDAC were analysed by Chi-square (or Fisher's test, when appropriate), while Student's T-test was employed for continuous variables.

Kaplan-Meier curves of OS were plotted. The log-rank test was used to compare the curves of patient subgroups. A Cox proportional hazards model was constructed to assess the role of fractalkine and its receptor in predicting the OS.

Analyses were done using Epi Info version 3.5.1 (Centers for Disease Control and Prevention (CDC), Atlanta, GA, USA) and STATISTICA 7.1 (StatSoft, Tulsa, OK, USA). For each test, only two-sided $P$-values lower than 0.05 were considered as statistically significant.

\section{RESULTS}

CX3CR1 expression in PDAC is associated with tumour glandular differentiation and PNI. We previously showed that the chemokine receptor CX3CR1 is upregulated in pancreatic cancer compared with normal exocrine tissue, and that receptor expression was involved in tumour PNI (Bazan et al, 1997). In this study, we investigated in an independent cohort whether the specific ligand CX3CL1 is also expressed in PDAC, and whether both molecules are upregulated already in pre-neoplastic lesions (PanINs).

In normal pancreas, CX3CR1 expression by IHC was faint to negative in exocrine cells but positive in endocrine islets (Figure 1A). Conversely, cancer cells in 56 of 104 (53.9\%) PDAC expressed CX3CR1. In PDACs, CX3CR1 expression was associated with a well-to-moderate differentiation $\left(65.1 \%\right.$ of $\mathrm{CX} 3 \mathrm{CR} 1^{+}$in G1/G2 PDAC vs $37.5 \%{\mathrm{CX} 3 \mathrm{CR} 1{ }^{+}}^{+}$in G3 PDAC; $\left.P=0.005\right)$ (Figure $1 \mathrm{~B}$ and $\mathrm{C}$ ), as well as with the presence of PNI $(63.1 \%$ of $\mathrm{CX}_{3} \mathrm{CR} 1^{+}$neural-invasive PDAC vs $38.5 \%$ of $\mathrm{CX} 3 \mathrm{CR} 1^{+}$nonneural-invasive PDAC, $P=0.01$ ) (Table 1), this latter being not associated with tumour grade. Notably, in our series the presence of PNI was not associated with tumour differentiation (40 of 63, $63.5 \%, \mathrm{G} 1-\mathrm{G} 2$ neuroinvasive cancers vs 24 out of $40,60 \%, \mathrm{G} 3$ neuroinvasive ones, $P=0.44$ ). In addition, by stratifying cancers according to their differentiation we found that $\mathrm{CX} 3 \mathrm{CR} 1^{+}$ differentiated tumours were more frequently neural invasive (30 out of $40,75 \%$ ) than CX3CR1 ${ }^{-}$cancers (10 out of $23,43.5 \%$; $P=0.008$ ), while in poorly differentiated cases the frequency of PNI was similar in CX3CR $1^{+}(10$ out of $15,66 \%)$ and in CX3CR $1^{-}$cancers (14 out of $25,56 \% ; P=0.37$ ) (Figure $1 \mathrm{G}$ ).

In the tumour microenvironment, vessels and infiltrating inflammatory cells were also CX3CR ${ }^{+}$(Figure 1B, inset).

In non-neoplastic pancreas, CX3CL1 was faintly expressed in exocrine cells and endocrine islets, and expressed by neural cell bodies (Figure 1D and E) but not by neural processes. In all, 70 of $104(67.3 \%)$ PDAC showed immunoreactivity for CX3CL1 (Figure 1F). No significant correlation was found between CX3CL1 expression and cancer features (Table 1), but the ligand was more frequently expressed in CX3CR $1^{+}(45$ out of $56,80.3 \%)$ than in CX3CR1 ${ }^{-}$(23 out of $48,51.1 \%$; $P=0.002$ ) PDAC.

At multivariate analysis, better tumour differentiation $(P=0.008)$, PNI $(P=0.03)$, and ligand expression $(P=0.003)$ were all independently associated with CX3CR1 expression (Table 2).

CX3CR1 expression in cancer is associated with better patient survival. We assessed patient survival according to CX3CR1 and CX3CL1 status in PDAC. Patients with CX3CR ${ }^{+}$PDAC had a longer survival (mean 22.6 months; 95\% CI, 15.7-29.5 months) than patients with receptor-negative cancers (14.45 months; $95 \% \mathrm{CI}$, 11.0-17.8 months), although the difference was not statistically significant (log-rank test, $P=0.07$ ). However, considering only patients with radical surgery and no surgery-related mortality, those with $\mathrm{CX} 3 \mathrm{CR} 1^{+}$PDAC had a significantly better survival (31.95 months; 95\% CI, 22.7-41.2 months) than those with CX3CR1-immunonegative cancers (18.9 months; 95\% CI, 14.922.9 months; log-rank test, $P=0.05$ ) (Figure $1 \mathrm{H}$ ). No survival difference was observed according to CX3CL1 status in PDAC $(P=0.95)$. In this set of patients, the analysis by Cox proportionalhazard model showed that the tumour expression of CX3CR1 was associated with a better survival (HR 0.56, 95\% CI, 0.32-1.00; $P=0.05$ ), independently of tumour grade and PNI. Adjusting the model by tumour stage resulted in a loss of statistical significance, although patients with $\mathrm{CX} 3 \mathrm{CR} 1^{+} \mathrm{PDACs}$ retained tendency to better survival (HR 0.58, 95\% CI, 0.32-1.04; $P=0.07$ ). 

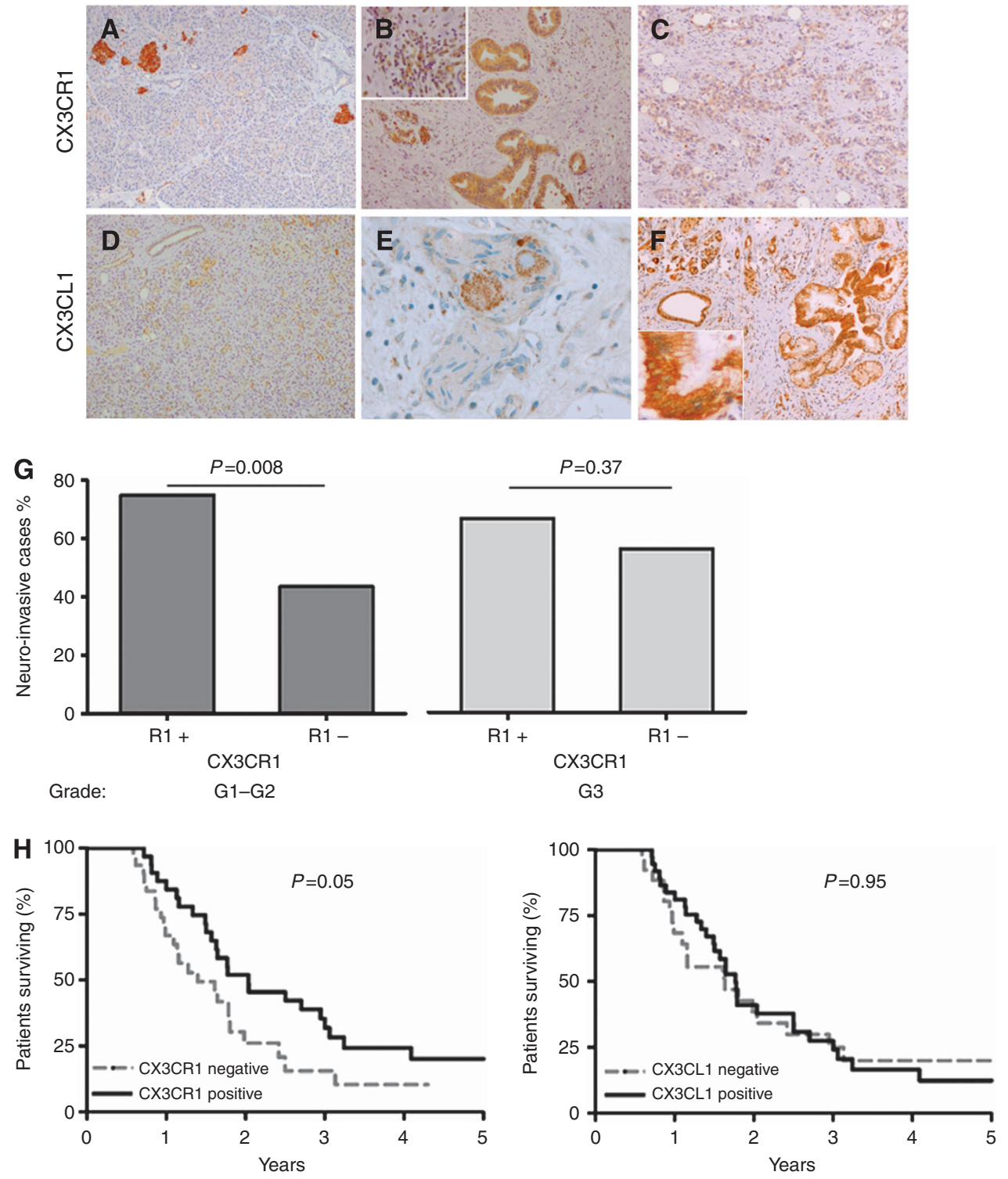

Figure 1. CX3CR1 and CX3CL1 expression in normal pancreas and in pancreatic cancer. (A) CX3CR1 expression in normal pancreas, (B) in welland $(\mathbf{C})$ in poorly differentiated PDAC, and (B, inset) in inflammatory cells in tumour microenvironment. (D) CX3CL1 expression in normal pancreas, $(\mathbf{E})$ in neural cell bodies, and $(\mathbf{F})$ in PDAC (box, $\times 40$ magnification of a CX3CL1 ${ }^{+}$PDAC). Objective magnification $\times 10(\mathbf{A}-\mathbf{D}$ and $\mathbf{F}) ;(E)$ and inset in (B), $\times 40$. (G) Frequency of CX3CR1 ${ }^{+}$and CX3CR1 ${ }^{-}$PDAC with PNI according to tumour differentiation (Grade, G1-G2 well-to-moderately differentiated PDAC; G3, poorly differentiated PDAC). (H) Kaplan-Meier curves for overall survival of patients after radical resection of PDAC $(n=67)$, according to the status of CX3-CR1 (left panel) and -CL1 (right panel) in cancer. $P$-values by log-rank test. ${ }^{*}$ indicates $P<0.05$.

Precursor lesions of pancreatic cancer express CX3CR1 and CX3CL1. We evaluated receptor and ligand status in PanINs to assess whether their expression appears before an invasive stage. In our series, 76 (73.1\%) PDAC specimens harboured precursor lesions. Precursor lesions were in general more frequently positive for CX3CR1 than PDACs $(61,80.3 \%$ vs $42,55.3 \%$, respectively; $P=0.002$ ), and specifically PanINs in specimens of undifferentiated G3 cancers were more frequently CX3CR1 ${ }^{+}$than PDAC ( 22 out of $28,78.6 \%$ vs 10 out of $28,35.6 \%$, respectively; $P=0.001$ ) (Figure 2A). CX3CL1 was also strongly upregulated in PanINs (40 out of $48,83.3 \%$ ) (Figure $2 \mathrm{~A}$ ) and, as observed for the receptor, ligand expression was higher in PanINs (26 out of $28,92.9 \%$ ) than in associated G3 PDACs (17 out of 28, 60.7\%; $P=0.005$ ) (Figure 2A).

Next, we studied ligand and receptor expression in precursor lesions according to their degree of dysplasia, characterised by morphological analysis and molecular phenotype (E-Cadherin and
p16/CDKN2A; Supplementary Figure S1). Of 15 PDAC specimens analysed, 8 out of 8 G1-G2 tumours were CX3CR1 ${ }^{+}$, while 3 out of $7 \mathrm{G} 3$ tumours were $\mathrm{CX} 3 \mathrm{CR} 1^{+}$. In the set of graded PanINs, the frequency of $\mathrm{CX} 3 \mathrm{CR} 1^{+}$precursor lesions increased from PanINs-1 to through PanINs-3 $(P<0.001$; Figure $2 \mathrm{~B})$; conversely, CX3CL1 expression decreased from PanIN-1 through PanIN-2 and PanIN-3 $(P=0.003$; Figure 2B). Representative images of CX3CR1 and CX3CL1 immunohistochemical staining in human PanINs are shown in Figure 3A.

Overall, upregulation of both CX3CR1 and CX3CL1 is an early feature of pancreatic carcinogenesis, being expressed already in PanINs-1. While positivity for both molecules is maintained through carcinoma stage if PDAC retains well-to-moderate differentiation, poorly differentiated tumours tend to lose their expression. These results indicate that the expression of the CX3CL1/CX3CR1 axis is a distinguishing feature of tumours with glandular morphology. 
Table 1. CX3CR1 and CX3CL1 expression in 104 PDAC according to patients' demographics and to tumour features

Expression in PDAC

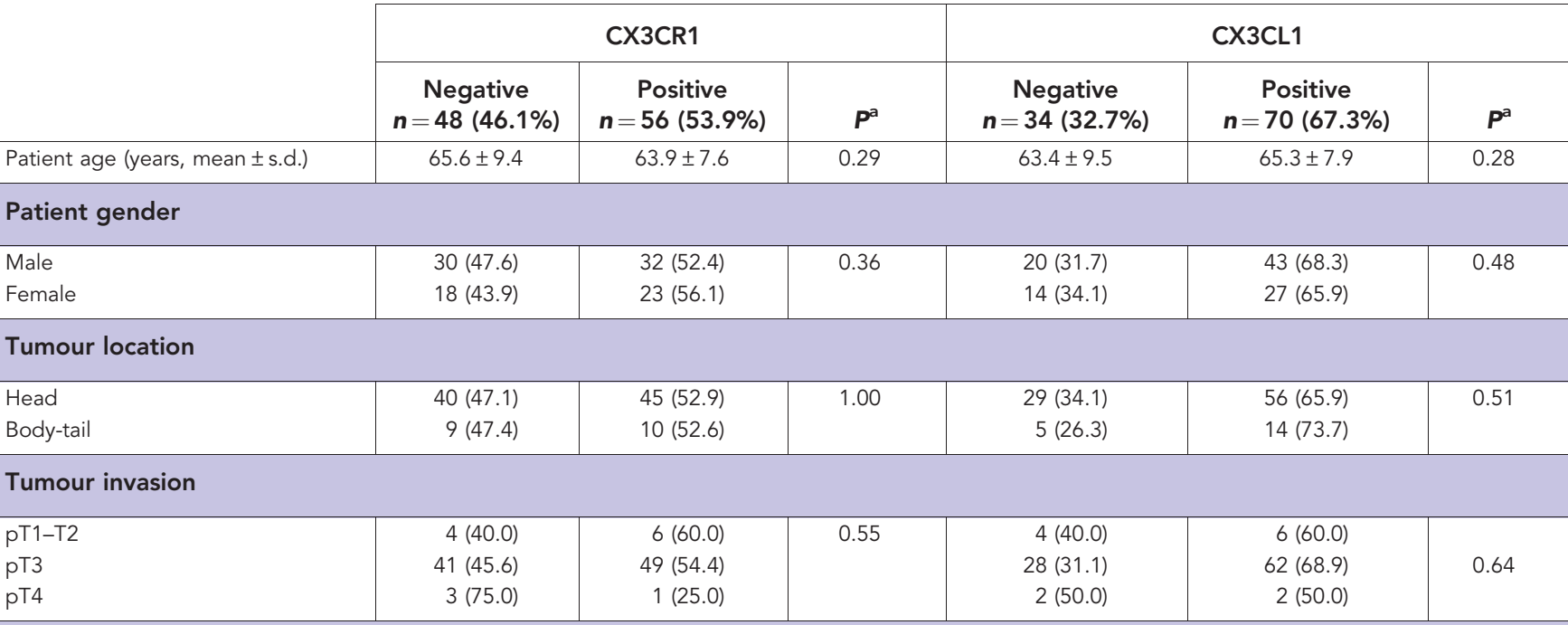

Nodal metastasis

\begin{tabular}{|c|c|c|c|c|c|c|}
\hline $\begin{array}{l}\mathrm{NO} \\
\mathrm{N}+ \\
\mathrm{Nx}\end{array}$ & $\begin{array}{r}3(25.0) \\
35(50.7) \\
10(43.5)\end{array}$ & $\begin{array}{r}9(75.0) \\
34(49.3) \\
13(56.5)\end{array}$ & $0.29^{b}$ & $\begin{array}{r}3(25.0) \\
25(36.2) \\
6(26.0)\end{array}$ & $\begin{array}{r}9(75.0) \\
44(63.8) \\
17(64.0)\end{array}$ & $0.22^{b}$ \\
\hline \multicolumn{7}{|l|}{ Tumour grade ${ }^{c}$} \\
\hline $\begin{array}{l}\text { G1-G2 } \\
\text { G3 }\end{array}$ & $\begin{array}{l}23(36.5) \\
25(62.5)\end{array}$ & $\begin{array}{l}40(63.5) \\
15(37.5)\end{array}$ & 0.005 & $\begin{array}{ll}21 & (33.3) \\
13 & (32.5)\end{array}$ & $\begin{array}{l}42(66.7) \\
27(67.5)\end{array}$ & 0.47 \\
\hline Tumour diameter (cm, mean \pm s.d.) & $3.6 \pm 2.1$ & $3.7 \pm 1.5$ & 0.94 & $3.5 \pm 1.9$ & $3.7 \pm 1.7$ & 0.66 \\
\hline \multicolumn{7}{|l|}{ Neural invasion } \\
\hline $\begin{array}{l}\text { No } \\
\text { Yes }\end{array}$ & $\begin{array}{l}24(61.5) \\
24(36.9)\end{array}$ & $\begin{array}{l}15(38.5) \\
41(63.1)\end{array}$ & 0.01 & $\begin{array}{l}15(31.2) \\
19(29.3)\end{array}$ & $\begin{array}{l}24(68.8) \\
46(70.7)\end{array}$ & 0.39 \\
\hline \multicolumn{7}{|l|}{ Vascular invasion } \\
\hline $\begin{array}{l}\text { No } \\
\text { Yes }\end{array}$ & $\begin{array}{l}23(43.4) \\
25(49.0)\end{array}$ & $\begin{array}{l}30(56.6) \\
26(51.0)\end{array}$ & 0.28 & $\begin{array}{l}18(34.0) \\
16(31.4)\end{array}$ & $\begin{array}{l}35(66.0) \\
35(68.6)\end{array}$ & 0.39 \\
\hline
\end{tabular}

Abbreviation: PDAC $=$ pancreatic ductal adenocarcinoma

a By chi-square or Fisher's exact test as appropriate, except for patients' age and tumour diameter comparisons, for which Student's t-test was used.

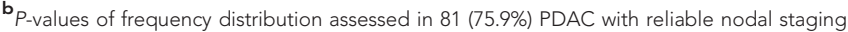

${ }^{\mathrm{c}}$ Not determined in one PDAC, treated with neo-adjuvant radio-chemio-therapy.

To confirm these findings, we studied precursor lesions in the PdxCre/LSL-Kras ${ }^{G 12 D}$ mouse model of pancreatic cancer. As in humans, the normal exocrine pancreas of mice killed before the development of precursor lesions ( $<6$ months) did not show CX3CR1 or CX3CL1 expression. Differently, CX3CR1 and CX3CL1 were expressed in the PanINs of mice older than 6 months of age, irrespectively of the degree of dysplasia (Figure 3B).

To evaluate whether precursor lesions can mimic PNI, we stained the pancreata of five PdxCre/LSL-Kras ${ }^{G 12 D}$ mice with antiS-100. Immunostaining revealed a small fraction (13 of $400 ; 3.25 \%)$ of precursor lesions either in proximity of, or in contact with, neural structures (Figure 3B).

CX3CR1 is unresponsive to inflammatory stimuli, but its expression is enhanced in spheroids in vitro, and in welldifferentiated tumour glands in vivo. We tested the responsiveness of CX3CR1 and-CL1 expression to cytokines in pancreatic tumour cells. In DT6606 cells, derived from tumours arising in PdxCre/ LSL-Kras ${ }^{G 12 D}$ mouse model, and in K8484 cells, derived from tumours of PdxCre/LSL-Kras ${ }^{G 12 D}-\operatorname{Tr} p 53^{R 172 H}$ model, the only observed change in CX3CR1 mRNA levels was a decrease following TNF- $\alpha$ plus IFN- $\gamma$ treatment in DT6606 cells. Differently, TNF- $\alpha$ plus IFN- $\gamma$ increased while TGF- $\beta$ downregulated the expression of CX3CL1 mRNA in both murine tumour cell lines, an effect obtained also by IL- $1 \beta$ and IL- 6 treatment in K8484 cells (Figure 4).

In human PDAC cells (A8184, AspCI, and MiaPacaII), inflammatory cytokines did not affect the mRNA levels of the receptor, but TNF- $\alpha$ plus IFN- $\gamma$ and IL- $1 \beta$ strongly increased the expression of the ligand. Like in cells derived from PdxCre/ LSL-Kras ${ }^{G 12 D}$ and $-\operatorname{Kras}^{G 12 D}-\operatorname{Tr} p 53^{R 172 H}$, IL-6 and TGF- $\beta$ stimulation downregulated the ligand in A8184 and AspCI cells (Figure 4).

The preferential expression of CX3CR1 in precursor lesions and differentiated PDAC, together with the lack of responsiveness to inflammatory signals, suggests that glandular differentiation may affect CX3CR1 status. Accordingly, we tested whether the formation of gland-like structures can induce CX3CR1 expression in vitro. DT6606 and K8484 cells propagation as 


\begin{tabular}{|c|c|c|c|}
\hline \multicolumn{4}{|c|}{$\begin{array}{l}\text { Table 2. Tumour differentiation, peri-neural invasion, and } \\
\text { expression are independently associated with CX3CR1 } \\
\qquad \begin{array}{l}\text { CX3CR1 expression }\end{array}\end{array}$} \\
\hline & OR & $95 \% \mathrm{Cl}$ & $P^{a}$ \\
\hline \multicolumn{4}{|c|}{ Tumour grade } \\
\hline $\begin{array}{l}\mathrm{G} 1-\mathrm{G} 2 \\
\mathrm{G} 3\end{array}$ & $\begin{array}{c}\text { 1.0 Ref. } \\
0.30\end{array}$ & $0.12-0.73$ & 0.008 \\
\hline \multicolumn{4}{|c|}{ Neural invasion } \\
\hline $\begin{array}{l}\text { No } \\
\text { Yes }\end{array}$ & $\begin{array}{c}\text { 1.0 Ref. } \\
2.63\end{array}$ & $1.08-6.39$ & 0.03 \\
\hline \multicolumn{4}{|c|}{ CX3CL1 expression } \\
\hline $\begin{array}{l}\text { Negative } \\
\text { Positive }\end{array}$ & $\begin{array}{c}\text { 1.0 Ref. } \\
3.99\end{array}$ & $1.57-10.14$ & 0.003 \\
\hline $\begin{array}{l}\text { Abbreviatio } \\
{ }^{a_{\text {By multivar }}}\end{array}$ & $\begin{array}{l}\text { e interval; } \\
\text { ssion analy }\end{array}$ & & \\
\hline
\end{tabular}

spheroids showed a spontaneous and significant CX3CR1 mRNA and protein increase as compared with monolayer cell culture, in which $<5 \%$ and $20 \%$ of cells, respectively, were CX3CR $1^{+}$. Immunofluorescence revealed a uniform CX3CR1 expression in the cells positioned in the outer portion of the glandular structure formed by DT6606 and K8484 spheroids. The same immunepositivity was detectable in human cancer AspCI cell spheroids, while in A8184 cells, receptor expression was not significantly increased in spheroids with respect to monolayers (Figure 5A-D).

To confirm the association between glandular differentiation and CX3CR1 expression, we grafted pancreatic tumour cells in syngenic C57BL/6 mice. Subcutaneous injection of DT6606 cells in 15 mice and of K8484 cells in 8 mice ensued in tumour growth in $11(73.3 \%)$ and in $8(100 \%)$ animals, respectively. The resulting tumours were well differentiated and showed intense and homogeneous CX3CR1 immunostaining. Differently, PANC02 cells efficiently propagated as undifferentiated cancers in 5 out of 5 mice, but none of these cancers expressed the receptor (Figure 5E).

\section{DISCUSSION}

Our extensive studies in human pancreatic cancer and precursor lesions, in a genetic mouse model, as well as in vitro and in vivo, elucidate important aspects of CX3-CR1-CL1 expression in pancreatic carcinogenesis. First, we found that human PanINs and well-differentiated PDACs express CX3CR1 more frequently than poorly differentiated cancers. Furthermore, CX3CR1 expression was significantly associated with PNI only in differentiated PDAC. The presence of the receptor already in pre-invasive precursor lesions indicates an early timing of expression in pancreatic carcinogenesis. Such an early appearance was experimentally mirrored by the results in the animal model. Next, the presence of the receptor in differentiated cancers would equip soon these tumours with the capability to follow a chemotactic drive, contributing to PNI (Marchesi et al, 2008). On the other side, our findings imply that poorly differentiated PDACs do not take advantage of CX3CL1-driven chemotaxis and adhesion in their spread. Such a difference in the expression of
A

G1-G2 PDACs

G3 PDACs
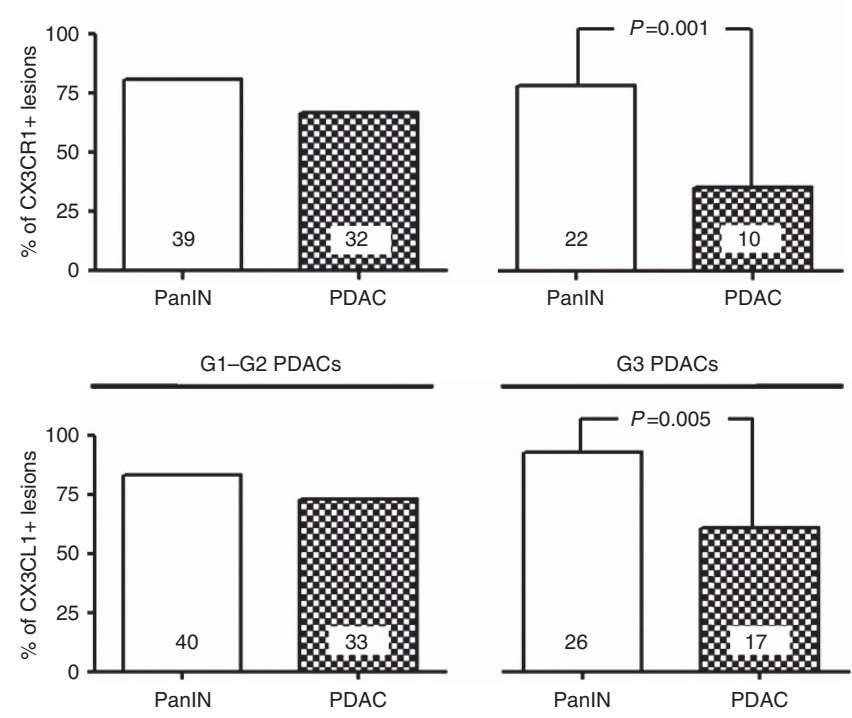

B

G1-G2 PDACs

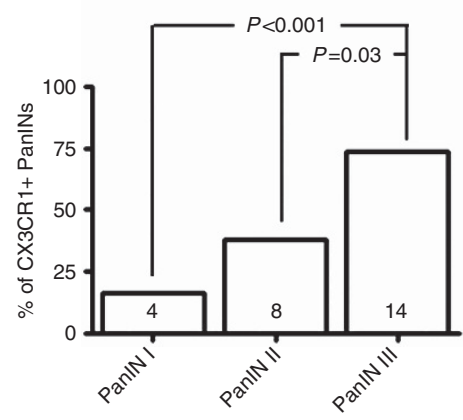

G3 PDACs
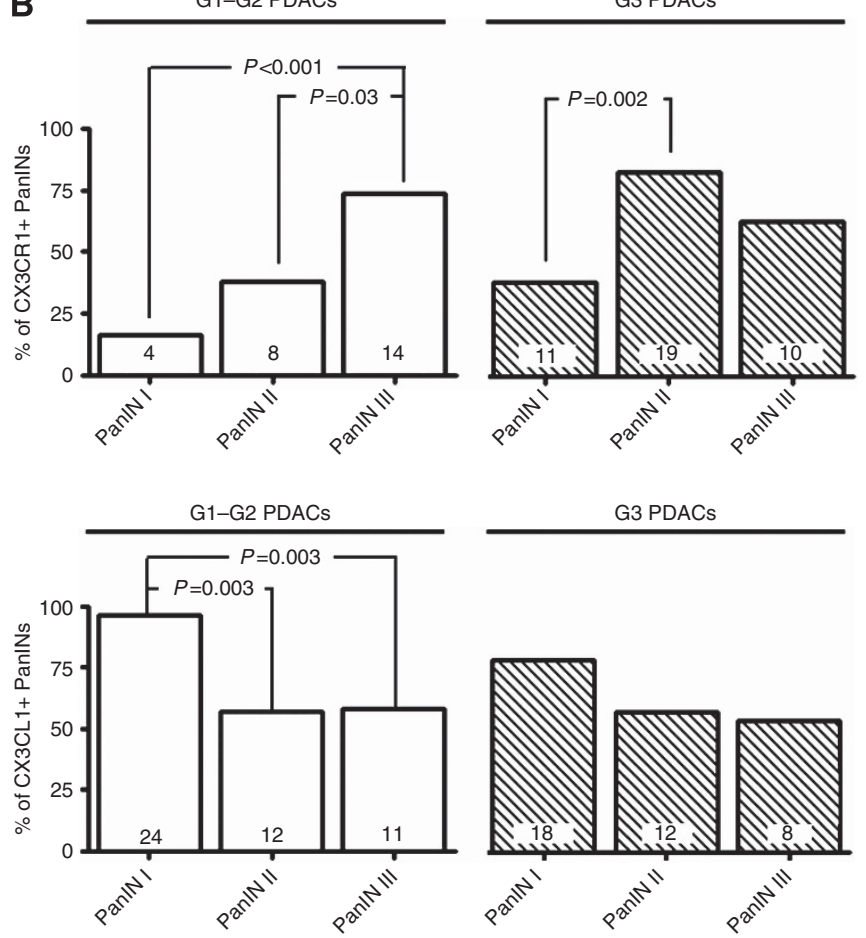

Figure 2. Expression of $\mathrm{CX} 3 \mathrm{CR} 1$ and $\mathrm{CX} 3 \mathrm{CL} 1$ in precursor lesions according to tumour differentiation and PanIN degree.

(A) Comparison of the expression rate of CX3CR1 (upper panels) and CX3CL1 (lower panels) in paired precursor lesions and invasive cancers within the same tissue specimens $(n=76)$, according to the degree of pancreatic cancer differentiation. Number within bars, number of specimens. (B) Rates of CX3CR1 ${ }^{+}$(upper panels) and CX3CL1 ${ }^{+}$(lower panels) PanINs according to their degree of dysplasia. Numbers within bars, number of PanINs. G1-G2 tumours, left panels; G3 tumours, right panels; P-values by Fisher's exact test.

chemotactic receptors depending upon tumour differentiation is not restricted to CX3CR1, as CXCR7 was conversely found to be more frequently expressed in poorly differentiated pancreatic cancers (Gebauer et al, 2011). Accordingly, tumour grade, an important determinant in PDAC outcome (Luttges et al, 2000; Helm et al, 2009), accounts for the differential expression of 
A
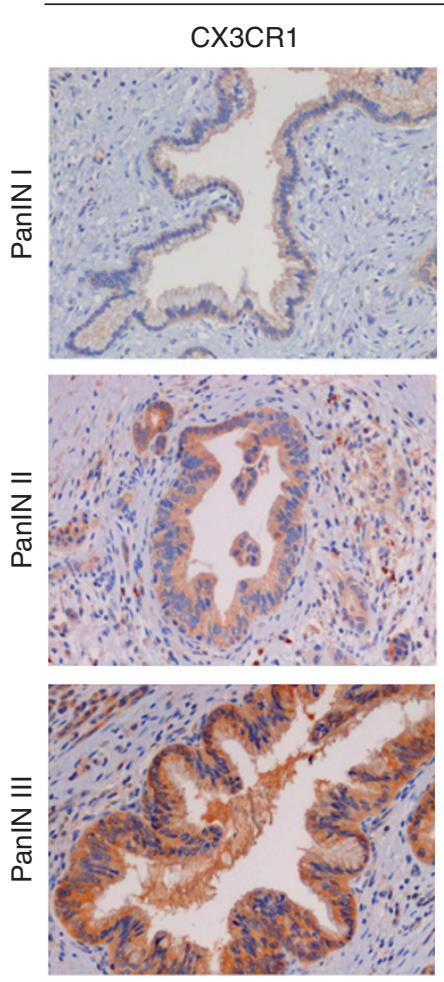

Human
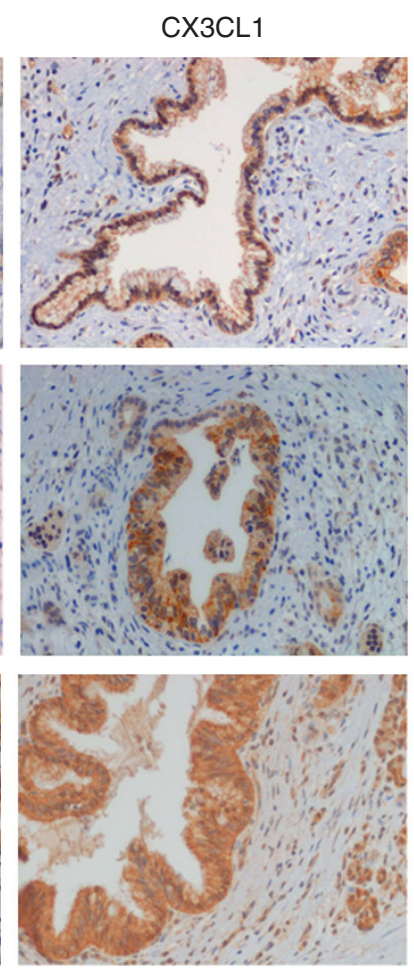

Mouse
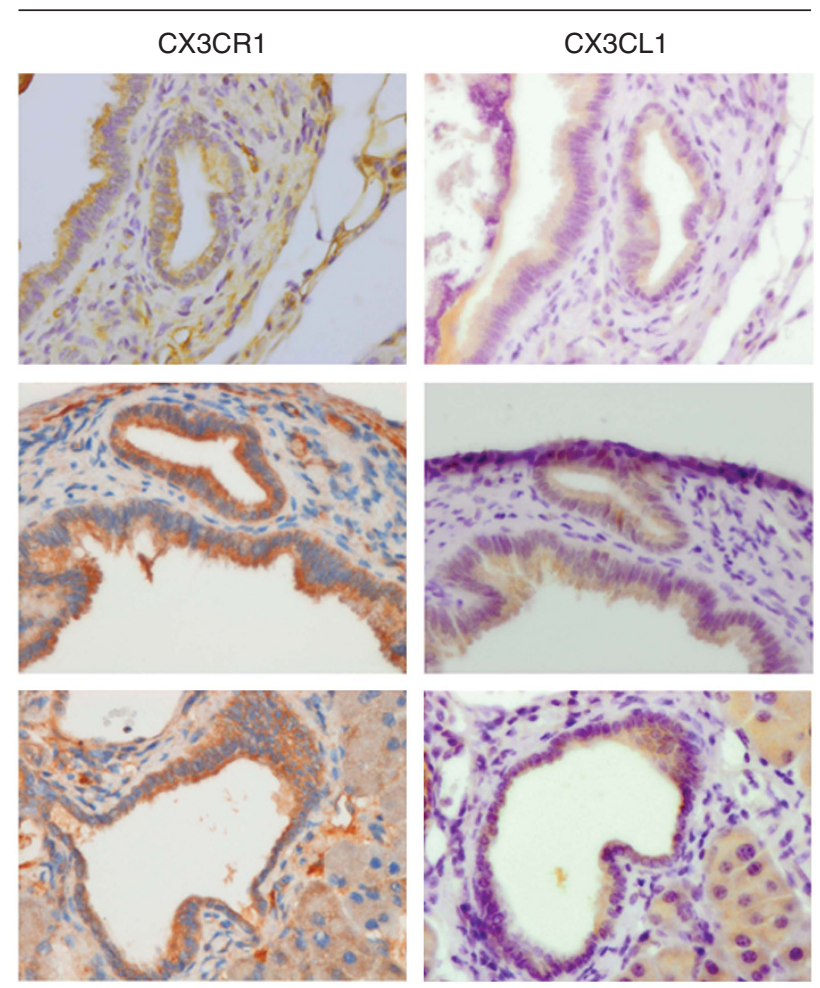

B

S100A4

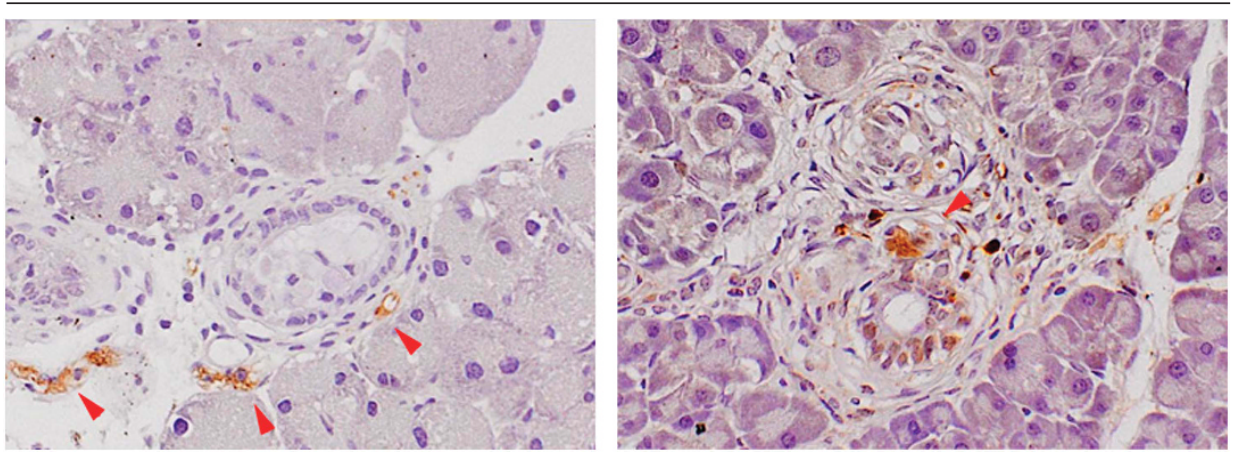

Figure 3. CX3CR1 and CX3CL1 expression in precursor lesions of pancreatic cancer. (A) Left panels, human PanINs; right panels, PanINs of $\mathrm{PdxCre/LSL-Kras}{ }^{G 12 D}$ mice. Objective magnification, $\times 20$ (human PanINs), and $\times 40$ (mice PanINs). (B) Precursor lesions adjacent to neural structures. Detection of precursor lesions close to (left panel) or in tight contact with (right panel) S-100 ${ }^{+}$neural structures (red arrows) in pancreata of 6-month-old PdxCre/LSL-Kras ${ }^{G 12 D}$ mice. Magnification, $\times 20$.

chemokine receptors. As the precursor lesions in the context of poorly differentiated PDAC expressed CX3CR1, we can infer that cancer cells no longer express this receptor when clonal selection privileges the outgrowth of undifferentiated clones. It is thus conceivable that the sensitivity of pancreatic cancer to chemokine attraction varies along tumour evolution (Kim et al, 2005; Buckle et al, 2012), such as changes in tumour differentiation.

The pro-invasive role of CX3CR1, which is foreseeable after the transition from PanIN to invasive cancer, remains otherwise elusive in pre-invasive lesions (Balkwill, 2012). In a mouse model of pancreatic cancer, PanIN cells can cross the basement membrane and delaminate in the microenvironment before any invasive behavior can be detected by histological criteria, indicating that PanINs may already harbour cells with invasive features (Rhim et al, 2012). Such invasive and tumour initiating cells from PanINs lacked E-Cadherin (Rhim et al, 2012), and in keeping with this notion we found a marked decrease in E-Cadherin expression in $\mathrm{CX}_{3} \mathrm{CR} 1^{+}$PanINs. Additional studies should assess whether delaminating cells from PanINs express CX3CR1, anticipating the involvement of chemotaxis in PNI.

We have previously reported the association among CX3CR1 expression, marked PNI, and shorter progression-free survival (Marchesi et al, 2008). In this independent cohort, we found that patients with $\mathrm{CX} 3 \mathrm{CR} 1^{+}$PDAC had a longer OS. Perineural invasion is a predictor of tumour recurrence, but tumour grade is the only histological feature of pancreatic cancer associated with worse survival (Helm et al, 2009; Shimada et al, 2011). Consistently, tumour grade, but not PNI, was a predictor of patient survival in our series, and the tumour expression of CX3CR1 retained prognostic value once adjusted for tumour grade and stage in a Cox model. Thus, the association between CX3CR1 tumour expression and better patient survival may simply reflect 

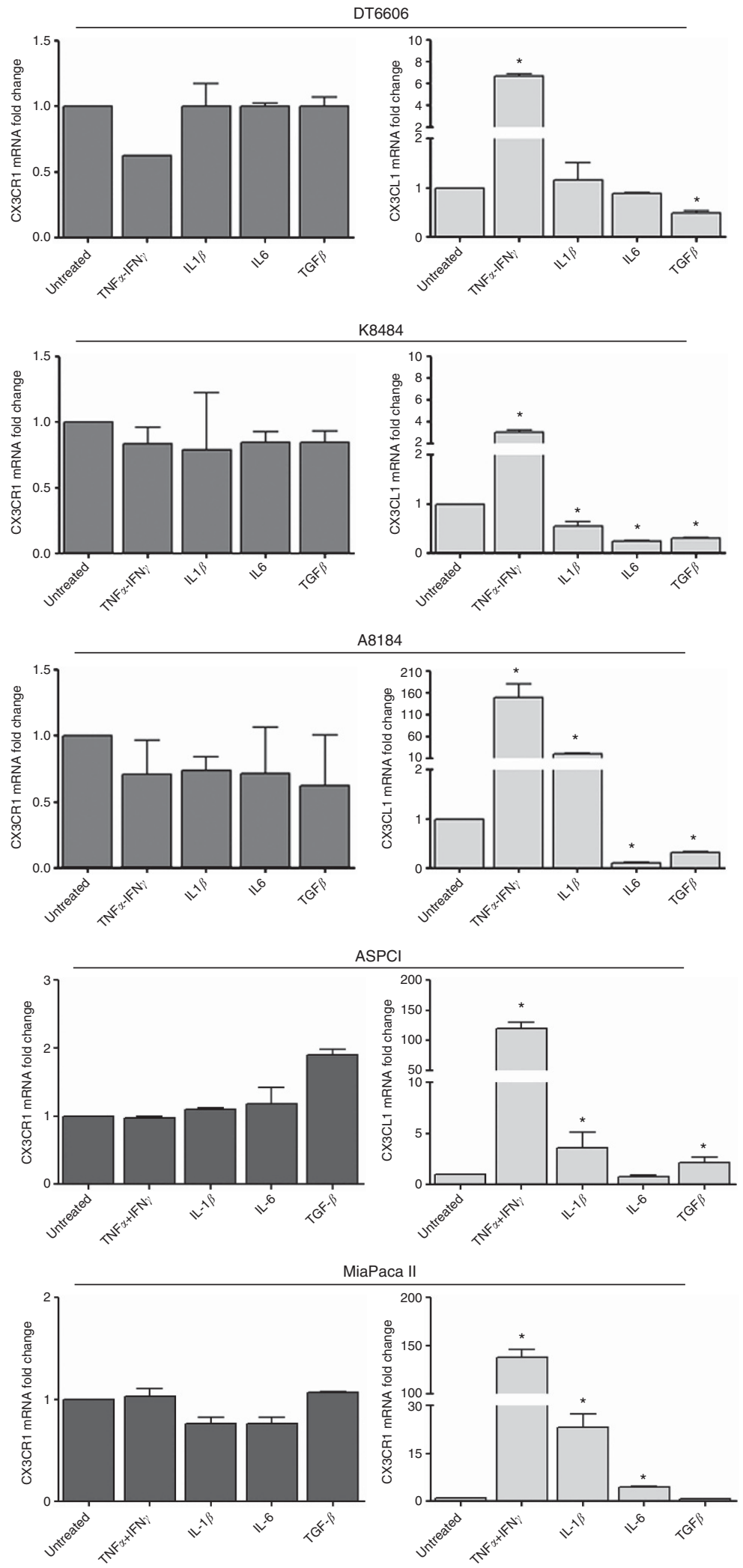

Figure 4. Effects of microenvironmental stimuli on CX3CR1 and CX3CL1 expression in pancreatic tumoral cells. CX3CR1 (left panels) and CX3CL1 (right panels) mRNA fold changes induced by stimulation with TNF- $\alpha+$ IFN- $\gamma$, IL-1 $\beta$, IL-6, and by TGF- $\beta$ in mouse DT6606 (PdxCre/ LSL-Kras ${ }^{G 12}$ model) and K8484 (PdxCre/LSL-Kras ${ }^{G 12 D}-T_{r p} 53^{R 172 H}$ model) cells, and in human A8184, AspCl, and MiaPacall pancreatic cancer cells. *indicates $P<0.05$.

an earlier disease. Differently, Xu et al (2012) reported that CX3CR1 status in PDAC has no prognostic value, while CX3CL1 expression would predict a worse prognosis. In this series, however, radical surgery was not considered, and average survival was almost half than in our, implying that patients with rather advanced disease have been studied. Considering that the invasive profile drawn by chemokine receptors changes with tumour evolution (Kim et al, 2005; Ottaiano et al, 2006), our results suggest 

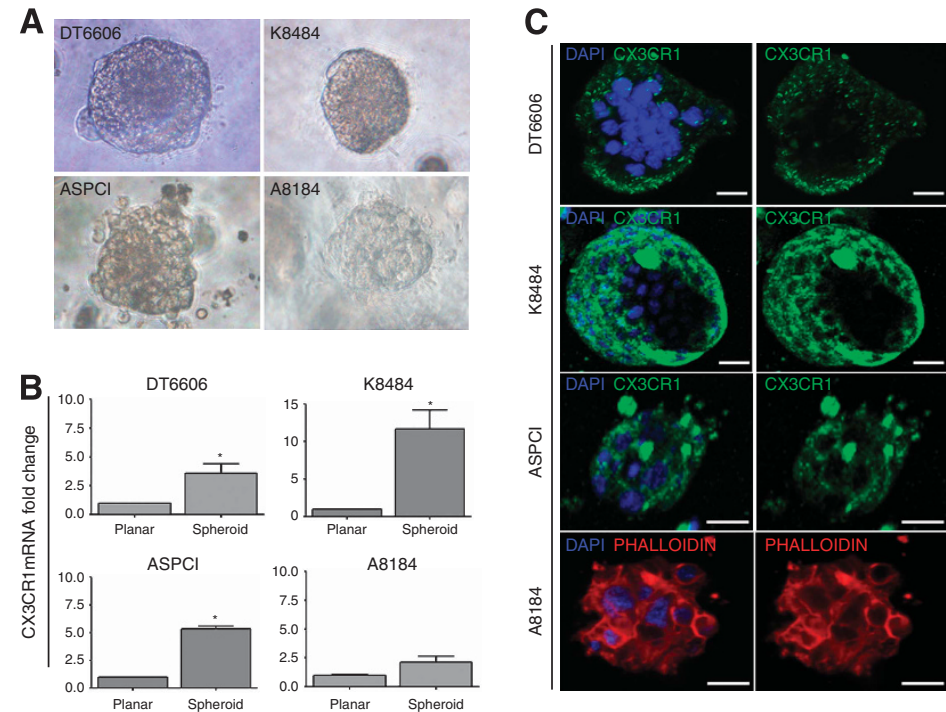
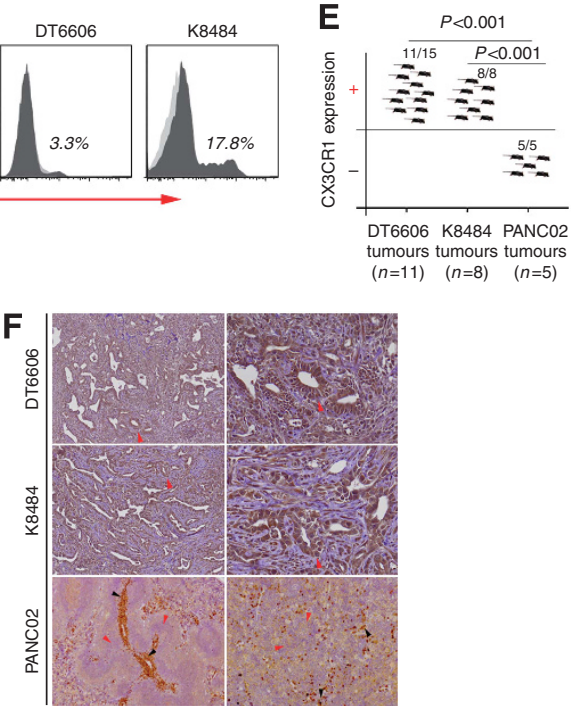

Figure 5. Effects on CX3CR1 expression of the three-dimensional organisation of pancreatic tumour cells in vitro, and of tumour differentiation in vivo. (A) Spheroids formed by DT6606, K8484, AspCl, and A8184, cells grown in Cultrex 3D bulk. Objective magnification $\times 40$. (B) CX3CR1 mRNA levels were significantly enhanced as compared with planar cell culture conditions in DT6606 cells (upper-left), K8484 (upper-right) and $\mathrm{AspCl}$ (down-left) but not in A8184 cells (down-right), grown as spheroids. (C) Immunofluorescence for CX3CR1 performed on spheroids, shows CX3CR1 expression in the outer spheroid portion in DT6606, K8484, and AspCl but not in A8184 cells (stained with phalloidin; scale bar, $10 \mu \mathrm{m}$ ). (D) Cyto-fluorimetric analysis for CX3CR1 of PANC02, DT6606, and K8484 cell monolayers. (E) Graph summarises the rate of tumours growth in C57BL/6 mice and the corresponding expression status of CX3CR1 according to the injected cell line. (F) CX3CR1 was expressed by DT6606 and K8484 cells grafted in syngenic C57BL/6 mice and growing as differentiated tumour glands, but not by PANC02 cells growing as undifferentiated cancer (black and red arrows, tumour and inflammatory infiltrating cells, respectively). ${ }^{*}$ indicates $P<0.05$.

that CX3CR1 could be foreseen as a biomarker paralleling early invasiveness, a feature that innovative imaging techniques might help to address (Buckle et al, 2012). If this were the case, then the axis CX3-CR1-CL1 would be a candidate target for interfering with invasion at the transition to invasive cancer.

In the second instance, our experimental results provide support to the associative data. CX3CR1 was unresponsive to inflammatory signalling in vitro, but was modulated by the structural organisation of tumour cells, both in vitro and in vivo. In parallel with findings in human PDAC, mouse tumour DT6606 cells expressed CX3CR1 in vitro only if cultured as spheroids, as they did in vivo growing as gland-forming tumours. Conversely, growth of undifferentiated PANC02 cells resulted in CX3CR1-negative cancers in vivo. Thus, experimental models confirming that tumour differentiation is crucial in setting CX3CR1 expression in tumour cell, reveal that the threedimensional organisation of neoplastic cells is a crucial factor for the expression of a chemotactic receptor. Although we did not investigate the signalling coupling the organisation of tumour cells with CX3CR1 expression, our data underline that the expression of the receptor is unlikely dependent upon microenvironmental cross-talk, rather being determined by tumour morphological features. Differently, CX3CL1 expression was strongly driven by inflammation in vitro. Pro-inflammatory TNF- $\alpha$ plus IFN- $\gamma$ induced a higher increase in CX3CL 1 mRNA in Kras-mutated than in isogenic but p53-mutated ductal cells, confirming that p53 damage dampens CX3CL1 responsiveness along tumour progression (Shiraishi et al, 2000; Algul et al, 2007; Jones et al, 2008; Sipos et al, 2009). These results help to explain for the reduced rate of CX3CL1 expression in PanINs with increasing dysplasia, known to be coupled with P53 damage (Remmers et al, 2011). The high rate of CX3CL1 expression in PanINs-1 is consistent with other data showing that the chemotactic recruiters of leukocytes appear with the first intraepithelial stages of human pancreatic carcinogenesis, decreasing thereafter (Hiraoka et al, 2011). The responsiveness of CX3CL1 to cytokines observed in pancreatic tumour cells also fits with its involvement in the tumour-stroma cross-talk contributing to the desmoplasic reaction (Hiraoka et al, 2011), as shown in chronic pancreatitis (Ceyhan et al, 2009). Joined with previous findings (Thomas et al, 2008), our results firmly indicate that the switch-on of chemotactic molecules is a common and early feature of pancreatic carcinogenesis, encouraging the development of strategies aimed to interfere with the CX3-CR1CL1 axis to constrain early on the invasiveness of differentiated pancreatic cancer.

\section{ACKNOWLEDGEMENTS}

We thank Dr DA Tuveson, Cambridge Research Institute, Cambridge, UK, for sharing PdxCre/LSL-Kras ${ }^{\mathrm{G} 12 \mathrm{D}}$ transgenic mice, and Dr Francesca Bergomas for experiments involving the generation of syngenic tumourgrafts. This research was funded by the Italian Minister of Health: grant 'Tumour stroma interaction, as therapy target in pancreatic cancer' (Ricerca Finalizzata 2005, no. 58). Additional fundings were provided to FN and PC by Italian Association for Cancer Research (AIRC), IG no. 11043 Ministero della Sanità (Progetto Integrato Oncologia) e Regione Piemonte 'Ricerca Industriale e Sviluppo Precompetitivo' (ONCOPROT and BIO-PRO), 'Converging Technologies' (BIOTHER), Progetti strategici su tematiche di interesse regionale o sovra regionale (IMMONC), Ricerca Sanitaria Finalizzata, and by AIRC 2011-Bando 5 per mille-Grant no. 12182 , and to FM by AIRC (Grant number MFAG-11 677).

\section{CONFLICT OF INTEREST}

The authors declare no conflict of interest. 


\section{REFERENCES}

Algul H, Treiber M, Lesina M, Schmid RM (2007) Mechanisms of disease: chronic inflammation and cancer in the pancreas-a potential role for pancreatic stellate cells? Nat Clin Pract Gastroenterol Hepatol 4(8): 454-462.

Balkwill FR (2012) The chemokine system and cancer. J Pathol 226(2): 148-157.

Bazan JF, Bacon KB, Hardiman G, Wang W, Soo K, Rossi D, Greaves DR, Zlotnik A, Schall TJ (1997) A new class of membrane-bound chemokine with a CX3C motif. Nature 385(6617): 640-644.

Buckle T, van Berg NS, Kuil J, Bunschoten A, Oldenburg J, Borowsky AD, Wesseling J, Masada R, Oishi S, Fujii N, van Leeuwen FW (2012) Noninvasive longitudinal imaging of tumor progression using an (111)indium labeled CXCR4 peptide antagonist. Am J Nucl Med Mol Imaging 2(1): 99-109.

Ceyhan GO, Deucker S, Demir IE, Erkan M, Schmelz M, Bergmann F, Muller MW, Giese T, Buchler MW, Giese NA, Friess H (2009) Neural fractalkine expression is closely linked to pain and pancreatic neuritis in human chronic pancreatitis. Lab Invest 89(3): 347-361.

Farrow B, Albo D, Berger DH (2008) The role of the tumor microenvironment in the progression of pancreatic cancer. J Surg Res 149(2): 319-328.

Gebauer F, Tachezy M, Effenberger K, von Loga K, Zander H, Marx A, Kaifi JT, Sauter G, Izbicki JR, Bockhorn M (2011) Prognostic impact of CXCR4 and CXCR7 expression in pancreatic adenocarcinoma. J Surg Oncol 104(2): 140-145.

Helm J, Centeno BA, Coppola D, Melis M, Lloyd M, Park JY, Chen DT, Malafa MP (2009) Histologic characteristics enhance predictive value of American Joint Committee on Cancer staging in resectable pancreas cancer. Cancer 115(18): 4080-4089.

Hermann PC, Huber SL, Herrler T, Aicher A, Ellwart JW, Guba M, Bruns CJ, Heeschen C (2007) Distinct populations of cancer stem cells determine tumor growth and metastatic activity in human pancreatic cancer. Cell Stem Cell 1(3): 313-323.

Hidalgo M (2010) Pancreatic cancer. N Engl J Med 362(17): 1605-1617.

Hingorani SR, Wang L, Multani AS, Combs C, Deramaudt TB, Hruban RH, Rustgi AK, Chang S, Tuveson DA (2005) Trp53R172H and KrasG12D cooperate to promote chromosomal instability and widely metastatic pancreatic ductal adenocarcinoma in mice. Cancer Cell 7(5): 469-483.

Hiraoka N, Yamazaki-Itoh R, Ino Y, Mizuguchi Y, Yamada T, Hirohashi S, Kanai Y (2011) CXCL17 and ICAM2 are associated with a potential anti-tumor immune response in early intraepithelial stages of human pancreatic carcinogenesis. Gastroenterology 140(1): 310-321.

Hwang RF, Moore T, Arumugam T, Ramachandran V, Amos KD, Rivera A, Ji B, Evans DB, Logsdon CD (2008) Cancer-associated stromal fibroblasts promote pancreatic tumor progression. Cancer Res 68(3): 918-926.

Jones S, Zhang X, Parsons DW, Lin JC, Leary RJ, Angenendt P, Mankoo P, Carter H, Kamiyama H, Jimeno A, Hong SM, Fu B, Lin MT, Calhoun ES, Kamiyama M, Walter K, Nikolskaya T, Nikolsky Y, Hartigan J, Smith DR, Hidalgo M, Leach SD, Klein AP, Jaffee EM, Goggins M, Maitra A, Iacobuzio-Donahue C, Eshleman JR, Kern SE, Hruban RH, Karchin R, Papadopoulos N, Parmigiani G, Vogelstein B, Velculescu VE, Kinzler KW (2008) Core signaling pathways in human pancreatic cancers revealed by global genomic analyses. Science 321(5897): 1801-1806.

Kim J, Takeuchi H, Lam ST, Turner RR, Wang HJ, Kuo C, Foshag L, Bilchik AJ, Hoon DS (2005) Chemokine receptor CXCR4 expression in colorectal cancer patients increases the risk for recurrence and for poor survival. J Clin Oncol 23(12): 2744-2753.

Luttges J, Schemm S, Vogel I, Hedderich J, Kremer B, Kloppel G (2000) The grade of pancreatic ductal carcinoma is an independent prognostic factor and is superior to the immunohistochemical assessment of proliferation. J Pathol 191(2): 154-161.

Mantovani A, Allavena P, Sica A, Balkwill F (2008) Cancer-related inflammation. Nature 454(7203): 436-444.

Mantovani A, Garlanda C, Allavena P (2010) Molecular pathways and targets in cancer-related inflammation. Ann Med 42(3): 161-170.

Marchesi F, Monti P, Leone BE, Zerbi A, Vecchi A, Piemonti L, Mantovani A, Allavena P (2004) Increased survival, proliferation, and migration in metastatic human pancreatic tumor cells expressing functional CXCR4. Cancer Res 64(22): 8420-8427.

Marchesi F, Piemonti L, Fedele G, Destro A, Roncalli M, Albarello L, Doglioni C, Anselmo A, Doni A, Bianchi P, Laghi L, Malesci A, Cervo L, Malosio M, Reni M, Zerbi A, Di Carlo V, Mantovani A, Allavena P (2008) The chemokine receptor CX3CR1 is involved in the neural tropism and malignant behavior of pancreatic ductal adenocarcinoma. Cancer Res 68(21): 9060-9069.

Olive KP, Jacobetz MA, Davidson CJ, Gopinathan A, McIntyre D, Honess D, Madhu B, Goldgraben MA, Caldwell ME, Allard D, Frese KK, Denicola G, Feig C, Combs C, Winter SP, Ireland-Zecchini H, Reichelt S, Howat WJ, Chang A, Dhara M, Wang L, Ruckert F, Grutzmann R, Pilarsky C, Izeradjene K, Hingorani SR, Huang P, Davies SE, Plunkett W, Egorin M, Hruban RH, Whitebread N, McGovern K, Adams J, Iacobuzio-Donahue C, Griffiths J, Tuveson DA (2009) Inhibition of Hedgehog signaling enhances delivery of chemotherapy in a mouse model of pancreatic cancer. Science 324(5933): 1457-1461.

Ottaiano A, Franco R, Aiello Talamanca A, Liguori G, Tatangelo F, Delrio P, Nasti G, Barletta E, Facchini G, Daniele B, Di Blasi A, Napolitano M, Ierano C, Calemma R, Leonardi E, Albino V, De Angelis V, Falanga M, Boccia V, Capuozzo M, Parisi V, Botti G, Castello G, Vincenzo Iaffaioli R, Scala S (2006) Overexpression of both CXC chemokine receptor 4 and vascular endothelial growth factor proteins predicts early distant relapse in stage II-III colorectal cancer patients. Clin Cancer Res 12(9): 2795-2803.

Pan Y, Lloyd C, Zhou H, Dolich S, Deeds J, Gonzalo JA, Vath J, Gosselin M, Ma J, Dussault B, Woolf E, Alperin G, Culpepper J, Gutierrez-Ramos JC, Gearing D (1997) Neurotactin, a membrane-anchored chemokine upregulated in brain inflammation. Nature 387(6633): 611-617.

Remmers N, Bailey JM, Mohr AM, Hollingsworth MA (2011) Molecular pathology of early pancreatic cancer. Cancer Biomark 9(1-6): 421-440.

Rhim AD, Mirek ET, Aiello NM, Maitra A, Bailey JM, McAllister F, Reichert M, Beatty GL, Rustgi AK, Vonderheide RH, Leach SD, Stanger BZ (2012) EMT and dissemination precede pancreatic tumor formation. Cell 148(1-2): 349-361.

Shimada K, Nara S, Esaki M, Sakamoto Y, Kosuge T, Hiraoka N (2011) Intrapancreatic nerve invasion as a predictor for recurrence after pancreaticoduodenectomy in patients with invasive ductal carcinoma of the pancreas. Pancreas 40(3): 464-468.

Shiraishi K, Fukuda S, Mori T, Matsuda K, Yamaguchi T, Tanikawa C, Ogawa M, Nakamura Y, Arakawa H (2000) Identification of fractalkine, a CX3C-type chemokine, as a direct target of p53. Cancer Res $\mathbf{6 0}(14)$ : 3722-3726.

Sipos B, Frank S, Gress T, Hahn S, Kloppel G (2009) Pancreatic intraepithelial neoplasia revisited and updated. Pancreatology 9(1-2): 45-54.

Thomas RM, Kim J, Revelo-Penafiel MP, Angel R, Dawson DW, Lowy AM (2008) The chemokine receptor CXCR4 is expressed in pancreatic intraepithelial neoplasia. Gut 57(11): 1555-1560.

Vonlaufen A, Joshi S, Qu C, Phillips PA, Xu Z, Parker NR, Toi CS, Pirola RC, Wilson JS, Goldstein D, Apte MV (2008) Pancreatic stellate cells: partners in crime with pancreatic cancer cells. Cancer Res 68(7): 2085-2093.

Wang J, Seethala RR, Zhang Q, Gooding W, van Waes C, Hasegawa H, Ferris RL (2008) Autocrine and paracrine chemokine receptor 7 activation in head and neck cancer: implications for therapy. J Natl Cancer Inst 100(7): 502-512.

Xu X, Wang Y, Chen J, Ma H, Shao Z, Chen H, Jin G (2012) High Expression of CX3CL1/CX3CR1 Axis Predicts a Poor Prognosis of Pancreatic Ductal Adenocarcinoma. J Gastrointest Surg 16(8): 1493-1498.

This work is published under the standard license to publish agreement. After 12 months the work will become freely available and the license terms will switch to a Creative Commons AttributionNonCommercial-Share Alike 3.0 Unported License.

Supplementary Information accompanies this paper on British Journal of Cancer website (http://www.nature.com/bjc) 